Results For the 18 patients with PulseRider implanted as a coil-adjunct device, the mean age was $60.7 \pm 8.9 \mathrm{yrs}$ and 16 were female. The mean aneurysm diameter was $6.6 \pm 2.2 \mathrm{~mm}$, height $5.3 \pm 1.7 \mathrm{~mm}$ and neck $4.8 \pm 1.5 \mathrm{~mm}$. Locations included the basilar apex (11), MCA bifurcation (4) and ACOMM (3). Thirteen of 18 were de novo aneurysms while the remainder (5) were treated in the setting of aneurysmal recurrence. The most common PulseRider placement was extra-aneurysmal (12/18), followed by intra-aneurysmal (4/18) and hybrid (2/18). Immediate angiographic occlusions were 66.6\% RR-I, $16.7 \%$ RR-II, $16.7 \%$ RR-III. There were no device related adverse events. There were 3 (16.7\%) procedure-related adverse events which did not result in neurological changes. Seven enrollments have 6 month follow up and all are RRI-II. Only 1 has one year angiographic follow up (RRI) adjudicated by the core lab, and 4 have clinical follow up (4/4 mRS 0-2). None of the target aneurysms have required retreatment.

Conclusions The results of the discontinued NAPA provide high quality data on the occlusion rates and safety profile for the PulseRider device. Further one year angiographic and clinical follow up will be reported when available.

Disclosures A. Spiotta: 1; C; Microvention. 2; C; Minnetronix, Penumbra, Cerenovus. 6; C; Cerenovus, Penumbra, Pulsar Vascular, Stryker, Microvention. K. Ebersole: None. J. Lena: None. R. Starke: 2; C; Medtronic Neurovascular, Penumbra, Cerenovus, Abbott. R. De Leacy: 6; C; Penumbra, Cerenovus, Siemens. A. Puri: 1; C; Stryker Neurovascular, Medtronic Neurovascular. 2; C; Stryker Neurovascular, Medtronic Neurovascular. D. Yavagal: 2; C; Medtronic Neurovascular, Rapid Medical, Steering Committee, Neuralanalytics. 6; C; Medtronic, Cerenovus/Johnson \& Johnson, Rapid Medical, Neuralanalytics. B. Bohnstedt: 2; C; Penumbra, Stryker, Medtronic. L. Rangel-Castilla: None. A. Cheema: None. J. Davies: 1; C; National Center for Advancing Translational Sciences of the National Institutes of Health under award number KL2TR001413 to the University of Buffalo. 2; C; Medtronic, Neurotrauma Science, LLC. 4; C; RIST Neurovascular. K. de Macedo Rodrigues: None. J. Grossberg: None. B. Howard: None. C. Kellner: 1; C; Penumbra, Siemens Corp. G. Lanzino: None. S. Tateshima: 2; C; Cerenovus, Medtronic, Neurovasc, Stryker. 4; C; Neurovasc.

\section{E-213 STENT-ASSISTED COILING OF CEREBRAL ANEURYSMS: HEAD TO HEAD COMPARISON BETWEEN THE NEUROFORM ATLAS AND EZ STENTS}

B Daou*, G Palmateer, J Linzey, B Thompson, N Chaudhary, J Gemmete, A Pandey. Neurosurgery, University of Michigan, Ann Arbor, MI

\subsection{6/neurintsurg-2020-SNIS.244}

Introduction The Neuroform Atlas stent is thought to have features allowing for an improved stent delivery system. We aimed to provide a head-to-head comparison between stentassisted coiling (SAC) using the Atlas and EZ stents.

Methods Patients treated with SAC were retrospectively evaluated. 77 aneurysms treated with the Atlas stent and 77 aneurysms treated with the EZ stent were included. Outcomes included angiographic occlusion per the Raymond-Roy (RR) scale, recanalization, retreatment and procedural complications.
Abstract E-213 Table 1 Baseline patient characteristics

\begin{tabular}{llll}
\hline & Atlas stent ( $\mathrm{n}=77)$ & EZ stent ( $\mathrm{n}=77)$ & P value \\
\hline Mean patient age (range) & $60.8(12.7)$ & $56.1(12.7)$ & 0.02 \\
Gender (\% Male/Female) & $16.9 / 83.1$ & $33.8 / 66.2$ & 0.2 \\
Mean aneurysm size (range) & $6.4(2.4)$ & $6.9(3.6)$ & 0.3 \\
Ruptured aneurysm (\%) & 0 & 3.9 & 0.2 \\
Aneurysm shape (\% saccular/fusiform) & $97.4 / 2.6$ & $88.3 / 11.7$ & 0.06 \\
Multilobed aneurysm & 5.2 & 2.6 & 0.7 \\
Location (\% Anterior/Posterior circulation) & $80.5 / 19.5$ & $71.4 / 28.6$ & 0.3 \\
Median number of stents deployed & 1 & 1 & 0.2 \\
Staged intervention (\%) & 7.8 & 10.4 & 0.6 \\
Y-stenting (\%) & 3.9 & 9.1 & 0.3 \\
Mean angiographic follow-up (range) & $8.7(2.7)$ & $25.1(11)$ & 0.0001 \\
Mean clinical follow-up (range) & $6.1(4.1)$ & $23.8(12.4)$ & 0.0001 \\
\hline
\end{tabular}

\section{Abstract E-213 Table 2}

\begin{tabular}{llll}
\hline & $\begin{array}{l}\text { Atlas } \\
\text { stent }\end{array}$ & $\begin{array}{l}\text { EZ } \\
\text { stent }\end{array}$ & P value \\
\hline Technical success (\%) & 100 & 96 & 0.2 \\
Immediate Raymond Roy 1 occlusion (\%) & 81.8 & 67.6 & 0.03 \\
Immediate Raymond Roy 2 occlusion (\%) & 18.2 & 21.6 & 0.8 \\
Immediate Raymond Roy 3 occlusion (\%) & 0 & 10.8 & 0.006 \\
Immediate Raymond Roy 1 and 2 occlusion (\%) & 100 & 89.2 & 0.0007 \\
Follow-up Raymond Roy 1 occlusion (\%) & 83.7 & 67.6 & 0.08 \\
Follow-up Raymond Roy 2 occlusion (\%) & 9.3 & 15.5 & 0.4 \\
Follow-up Raymond Roy 3 occlusion (\%) & 7 & 16.9 & 0.16 \\
Follow-up Raymond Roy 1 and 2 occlusion (\%) & 93 & 83.1 & 0.16 \\
Recanalization (\%) & 7 & 12.7 & 0.5 \\
Retreatment (\%) & 4.6 & 14.1 & 0.009 \\
Thrombo-embolic and hemorrhagic complications & 6.5 & 10.4 & 0.6 \\
(\%) & & & \\
Complication with new neurological deficit (\%) & 1.3 & 2.6 & 1 \\
\hline
\end{tabular}

Results The Atlas and EZ stent groups had overall similar baseline characteristics. With the Atlas stent, technical success was $100 \%$ and immediate RR1 occlusion was $81.8 \%$. Followup RR1 was achieved in $83.7 \%$. Recanalization rate was $7 \%$ and retreatment rate was $4.6 \%$. Complication rate was $6.5 \%$ (new neurological deficit in 1.3\%). With the EZ stent, technical success was $96 \%$ and immediate RR1 occlusion was $67.6 \%$ and follow-up RR1 occlusion was $67.6 \%$. Recanalization rate was $12.7 \%$ and retreatment rate was $14.1 \%$. Complication rate was $10.4 \%$ (new neurological deficit in $2.6 \%$ ). The rate of immediate RR1 occlusion ( $p$ 0.03) was significantly higher with the Atlas stent and the rate of follow-up RR1 occlusion ( $p$ 0.08) was non-significantly higher with the Atlas stent. The recanalization rate was non-significantly lower with the Atlas stent ( $p$ 0.5); the retreatment rate was significantly lower with the Atlas stent (p 0.009). There was no significant difference in the complication rate ( $\mathrm{p} 0.6)$.

Conclusion SAC with the Atlas stent is safe and effective and shows better immediate results as compared to the EZ stent, with improved overall follow-up outcomes.

Disclosures B. Daou: None. G. Palmateer: None. J. Linzey: None. B. Thompson: None. N. Chaudhary: None. J. Gemmete: None. A. Pandey: None. 